Farklı rotary

sistemlerin post-core ile restore edilmiş dişlerin kırılma direnci üzerine etkisi

\section{Effect of different rotary systems on fracture resistance of post-core reconstructed teeth}

\section{Yrd. Doç. Dr. Oğuzhan Görler}

Cumhuriyet Üniversitesi, Diş Hekimliği Fakültesi, Protetik Diş Tedavisi A.D., Sivas

\section{Yrd. Doç. Dr. Recai Zan}

Cumhuriyet Üniversitesi, Diş Hekimliği Fakültesi, Endodonti A.D., Sivas

Yrd. Doç. Dr. Demet Altunbaş

Cumhuriyet Üniversitesi, Diş Hekimliği Fakültesi, Endodonti A.D., Sivas

Arş. Gör. Melih Ülgey

Cumhuriyet Üniversitesi, Diş Hekimliği Fakültesi, Protetik Diş Tedavisi A.D., Sivas

Geliş tarihi: 19 Nisan 2017

Kabul tarihi: 03 Haziran 2017

doi: 10.5505/yeditepe.2017.97269

\section{Yazışma adresi:}

Yrd. Doç. Dr. Oğuzhan Görler

Cumhuriyet Üniversitesi, Dis Hekimliği Fakültesi Protetik Diş Tedavisi A.D., 58140 Sivas, Türkiye Tel: +903462191010/ 2764

E-posta: oguzhangorler@gmail.com
ÖZET

Amaç: Bu çalışmada, One Shape New Generation (OSNG; MicroMega, Besancon, Fransa), ProTaper Gold (PTG; Dentsply Maillefer, Ballaigues, İsviçre) ve K3XF (SybronEndo) enstrümantasyon sistemlerinin post-core materyallerin yerleştirildiği köklerin kırılma direnci üzerine etkisi karşılaştırıldı. Gereç ve Yöntem: Altmış insan tek köklü mandibular premolar diş rastgele olarak 3 gruba ayrıldı $(n=20)$. Aynı uzunluk ve kalınlıklarda standardize edilen kökler, One-Shape New Generation (OSNG), ProTaper Gold (PTG) and K3XF aletleri kullanılarak prepare edildi. Prepare edilen kök kanalları AH-26 kullanılarak dolduruldu. Daha sonra, post-core materyalleri kök kanallarına yerleştirildi ve kompozit ile restore edildi. Daha sonra örnekler, kökleri kırmak için gereken kuvvetin belirlenmesi amacıyla vertikal yüke maruz bırakıldı. Veriler, tek yönlü ANOVA ve Tukey'in post-hoc testleri kullanılarak istatistiksel olarak analiz edildi.

Bulgular: OSNG grubu, diğer tüm gruplarla kıyaslandığında istatistiksel olarak daha yüksek kırılma direnci dereceleri sağlamıştır $(P<0,05)$. PTG grubu, K3XF grubuna göre istatistiksel olarak daha yüksek kırılma direnci değerleri göstermiştir $(P<0,05)$.

Sonuçlar: Bu çalışmanın koşulları altında, tüm enstrümantasyon sistemleri farklı kırıma direnci değerleri ile ilişkilendirilmiştir. OSNG enstrümanları kök dentininin en yüksek direnç derecesine neden olmuştur. Farklı enstrümantasyon sistemleri ile kök kanal preparasyonu, protezlerin uzun süreli kullanımı açısından daha dayanıklı bir altyapı elde etmenin etkili aşamalardan biri olarak görülmüştür.

Anahtar Kelimeler: Döner sistemler, post-core, kırılma direnci

\section{SUMMARY}

Objectives: The present study compared the effect of OneShape New Generation (OSNG; MicroMega, Besancon, France), ProTaper Gold (PTG; Dentsply Maillefer, Ballaigues, Switzerland) and K3XF (SybronEndo) instrumentation systems on fracture resistance of roots in which post-core materials were placed.

Materials and Methods: Sixty extracted human single-rooted mandibular premolar teeth were randomly assigned to 3 groups $(n=20)$. The root canals that standardized in the same length and thicknesses were instrumented using the OneShape New Generation (OSNG), ProTaper Gold (PTG) and K3XF instruments. The prepared root canals were filled with using $\mathrm{AH}-26$. Then, the post-core materials were placed into the root canals and restored with composite. The specimens were then exposed to a load to determine the force required to fracture the roots. The data were statistically analyzed using one-way ANOVA and Tukey's post-hoc tests.

Results: The OSNG group demonstrated statistically significantly higher degrees of fracture resistance compared to all other groups $(P<0.05)$. The PTG group indicated significantly higher fracture resistance values than K3XF group $(P<0.05)$. 
Conclusion: Under the conditions of this study, all instrumentation systems were associated with different fracture resistance values. OSNG instruments caused the highest degree of root dentin resistance. The root canal preparation with different instrumentation systems were seen as one of the effective stages to obtain a more durable substructure in terms of long term using of prosthesis. Key words: Rotary systems, post-core, fracture resistance

\section{GíRiş}

Başarılı bir endodontik tedavinin en önemli aşamalarından biri olan kök kanallarının biyomekanik preparasyonu, kanal tedavili dişlere yapılan konservatif veya protetik tüm restorasyonların uzun dönem başarısı açısından önemli bir basamaktır. ${ }^{1}$ Kök kanal tedavileri sırasında alet kırılması, kök kanal transportasyonu, basamak oluşumu ve perforasyon gibi istenmeyen komplikasyonlar meydana gelebilir. ${ }^{2-4}$ Bunların yanısıra, kök kanal preparasyonu kök dentininde kırık ve çatlak gibi dişin çekimi ile sonuçlanabilecek zararlar da meydana getirebilir. ${ }^{5}$

Kök kanal şekillendirilmesi esnasında meydana gelen bir çatlak veya kökte dikey yönde oluşabilecek vertikal bir kök kırığı, dişin çekilmesine neden olabileceği için tedavi görmüş dişlerin prognozunu olumsuz yönde etkileyen en önemli komplikasyondur. Kök kanal şekillendirilmesi sırasında meydana gelebilecek kök dentin çatlaklarına birçok etken neden olabilir. ${ }^{6}$ Ancak endodontik açıdan bu faktörlerin en önemlilerinden biri kök kanal genişletme sistemleridir. Yapılan bir araştırmada, kök kanallarının hazırlanması sırasında meydana gelen kök kırıkları ile kullanılan $\mathrm{Ni}$ - Ti rotary aletler arasında yakın bir ilişki bulunmuştur. Bununla birlikte, burkulma konsantrasyonu ve apikal stresin tercih edilen eğelerin tasarımlarından etkilendiğini iddia etmişlerdir.7 Kök kanal preparasyonu için tercih edilen rotary aletleri, kök kanalları içerisinde rotasyonel kuvvet uygulamaktadır. Bu kuvvet de kök dentininde mikro kırık ve çatlak oluşumuna yol açabilmektedir. Meydana gelen dentin defektlerinin tipi ve büyüklüğü kullanılan eğenin bıçak dizaynına, uç konfigürasyonu, konikleşme açısı, yiv formları ve hareket etme şekilleri arasındaki ilişkiye bağlıdır. ${ }^{8}$

Diş hekimliğinin tedavi başarısının uzun dönemde değerlendirmelerinde önemli araştırma alanlarından biri endodontik işlem uygulanmış dişlere restorasyon uygulanmasıdır. ${ }^{9,10} \mathrm{Bu}$ uygulamanın henüz konsensüse varılmamış birçok yönü bulunmaktadır. Genel olarak vital dişe göre endodontik işlem uygulanmış dişin post yerleştirmesi sırasında ve daha sonraki klinik kullanım döneminde çiğneme kuvvetlerine maruz kalması ile birlikte kırılmaya karşı daha hassas olduğu bilinmektedir. Klinik işlemler ve kullanılan materyaller açısından çok sayıda karar vermeyi zorlaştıran durum bulunmaktadır. ${ }^{11}$ Klinik uygulamada endodontik işlem ve yapılan restorasyon sonrası kanal tedavili dişin kırılması önemli bir başarısızıktır. ${ }^{12}$ Özellikle sabit ve hareketli protezlerde ayak diş olarak kullanılarak uzun dönem başarı hedeflenen ve kanal tedavisi uygulanan dişlerde oluşan kök kırıkları, klinik başarı oranını olumsuz yönde etkilemektedir. ${ }^{13,14}$ Hareketli protezlerde çok daha kritik bir görevi olan ve kronlanan kanal tedavili dişlerde oluşan kök kırıkları beklenmedik diş kayıplarına neden olmaktadır. ${ }^{14}$ Klinik başarıyı arttırmak için mümkün olduğunca daha uzun süre kullanılabilen restorasyonların yapılması diş hekimlerinin önemli bir beklentisidir. ${ }^{15,16}$

Kök kırıklarının sebepleri, kırılmaların önüne geçebilmek için farklı araştırmalara konu olmaktadır. Araştırıcılar kırılma sebepleri üzerinde dururlarken kanal tedavili dişlere uygulanan farklı post sistemlerinin, ${ }^{13,17-19}$ kanal tedavisi esnasında uygulanan yöntemlerin ve uygulama aletlerinin, dişlerin yapısında meydana gelebilecek streslerin ve farklı üst yapı çalışmaları için kullanılan restoratif materyallerin etkin olabileceklerine dikkati çekmişlerdir. ${ }^{13,20,21}$ Gerek preparasyon yöntemi gerek kullanılan post materyali gerekse de üst yapıda kullanılan restoratif materyalin kırılma üzerine etkisinin değerlendirilmesi yapılırken tüm bu faktörlere post yüzey özelliğine göre post ile diş kökü arasındaki bağlantıya katkı sağlayan ve stres dağılımını dengeleme rolü olan yapıştırma materyalini de hesaba katmakta fayda vardır. ${ }^{22,23}$ Öyle ki post ve diş arasındaki yapışmanın etkinliğini artırmak için prepare edilmiş kök kanalında veya uygulanan post üzerinde kimyasal ajanların kullanıldığı çalışmalar da literatürdeki yerlerini almıştır. ${ }^{24,25}$

Post uygulamalarının kök kanalları üzerinde oluşturduğu streslerin farklııkları üzerine yapılan çalışmalara katkıda bulunmak adına bu çalışmanın amacı, üç farklı rotary sistemi ile yapılan kök kanal preparasyonunun prefabrik post uygulanmış dişlerin kırılma dirençleri üzerindeki etkilerini incelemek ve karşılaştırmaktır.

\section{GEREÇ VE YÖNTEM}

\section{Dişlerin Seçimi ve Preparasyon}

Bu çalışmada ortodontik veya periodontal sebeplerle çekilmiş 60 adet tek kök tek kanallı mandibular premolar insan dişi kullanıldı. Dişlerin çekim nedenleri bu çalışma ile ilişkili değildir. Tüm dişler farklı açılardan alınan dijital radyografilerle değerlendirildi ve apeksi tam oluşmamış, birden fazla kök kanalına sahip, kalsifiye kanallı, internal veya eksternal kök rezorbsiyonu bulunan dişler çalışmaya dahil edilmedi. Daha sonra dişlerin üzerindeki yumuşak dokular ve diş taşları küret kullanılarak temizlendi. Dişler laboratuar işlemleri başlayıncaya kadar distile su içerisinde saklandı. Dişlerin kuronları, kole seviyesinden yüksek devirli ve su soğutmalı bir elmas frezle kök boyları $14 \mathrm{~mm}$ olacak şekilde ayarlanarak kesildi. Daha sonra kanallar boşaltılarak 10 numaralı K tipi eğe (Dentsply 
Maillefer, Ballaigues, İsviçre) kök ucuna kadar ilerletildi ve gerçek kök kanal boyu saptandı. Çalışma boyu (ÇB) bu boydan $1 \mathrm{~mm}$ kısa olacak şekilde belirlendi. Kök kanalları herbir eğe kullanımının ardından \% 1'lik $\mathrm{NaOCl}$ solüsyonu ile irrige edildi.

\section{Deney Grupları ve Preparasyon İşlemleri OSNG Grubu}

Kanal preparasyonu OSNG Ni-Ti döner eğe sistemi ile 300 rpm hızda, $2 \mathrm{Ncm}$ tork ayarında elektrikli motor (X-Smart, Dentsply Maillefer) kullanılarak yapıldı. Kanallar 0,06 açılı 25 no.lu eğe ile çalışma boyunda ve dengeli kuvvetle şekillendirme prosedürü kullanılarak şekillendirildi.

\section{K3XF Grubu}

Kanal preparasyonu K3XF Ni-Ti döner eğe sistemi ile 300 rpm hızda, $2 \mathrm{Ncm}$ tork ayarındaki elektrikli motor (X-Smart, Dentsply Maillefer) kullanılarak yapıldı. 0,10 açılı 25; 0,08 açılı 25; 0,06 açılı 40, 35, 30 no.lu eğeler sırasıyla crown down tekniğiyle kullanıırken, 0,06 açılı 25 no.lu eğe çalışma boyunda kullanılarak preparasyon tamamlandı.

\section{PTG Grubu}

Kök kanalları, tork kontrollü endodontik motor ile (X-Smart, Dentsply Maillefer) PTG eğeleri kullanılarak prepare edildi. Eğeler aşağıdaki sırayla kullanıldı: SX eğesi (ÇB'nun yarısı), S1 ve S2 eğesi (ÇB'nun 2/3), F1 eğesi (boyut 20, 0,07 açılı) ve F2 (boyut 25, 0,08 açılı) eğeleri (Tam ÇB'da). Tüm PTG aletleri 2 Ncm'lik bir tork ile 300 dev/dak'da kullanıldı.

Kök kanal dolumu $\mathrm{AH}-26$ kanal patı kullanılarak lateral kondensasyon tekniğiyle yapıldı. Kök kanal dolumlarının tamamlanmasının ardından, dolum yapılan kökler mekanik strese maruz bırakılmadan yarısına kadar ısıl yöntem ile boşaltıldı. Kanal duvarları debris ve guttadan arındırıldı. $9 \mathrm{~mm}$ uzunluğunda prefabrike postlar, yarısına kadar boşaltılan köklere eşit tur sayısı ile cam iyonomer siman kullanılarak yerleştirildi. Postların tatbiki için uygulanan başlık kısımlarının, dekoronalize edilen kesit alanına temas etmesine özen gösterildi. Kesit seviyesinden itibaren başlık kısımlarının etrafı akışkan rezin ile koronalize edildi. Başlıkların tepe kısımları, kırılma dayanım testi için kullanılacak başlık ucuna direkt temas etmesi için açık bırakıldı. Hazırlığı tamamlanan örneklerin test esnasında periodontal ligamenti taklit etmesi ve kırılma aşamasında hareket alanı oluşturabilmesi için kök yüzeyleri polieter ölçü maddesi olan silikon ile kaplandı. Test cihazına uygun kalıplar halinde soğuk akrilikten hazırlanan bloklara gömüldü. Örnekler hazırlandıktan sonra $37^{\circ} \mathrm{C}^{\prime}$ de 24 saat bekletildi.

\section{Kırılma Testi Uygulaması}

OSNG, K3XF ve PTG NiTi eğe sistemleri ile prepare edilen örnekler Universal test cihazı (LF Plus, LLOYD, Instrument, Ametek Inc, England) ile vertikal yüke maruz bırakıldı. Cihazın (H5K-S, Haunsfield Tenso-meter, Haunsfield Test Equipment Ltd, Redhill, Eng- land) hızı 5 mm/dak olacak şekilde ayarlandı. Yükleme, aralarında $10 \mathrm{~mm}$ mesafe bulunan $4 \mathrm{~mm}$ çaplı paralel çubuk destekler arasına konan örneklere, yine bunlara paralel ve merkezi ekseni tam ortada bulunan $4 \mathrm{~mm}$ çaplı üçüncü bir çubuk vasıtası ile vertikal olarak yapıldı. Post uygulanarak restore edilmiş olan köklere 50+/-16 N/dk değerindeki yük standartlarda belirtildiği gibi kırılma gerçekleşinceye kadar uygulanmıştır. Örnekler kırıldığı anda cihazın uyguladığı kuvvet bilgisayar ortamına kaydedilerek standartlarda açıklanan formülle hesaplandı Kırılma kuvveti "newton" (N) cinsinden kaydedildi.

\section{İstatistiksel analiz}

Kırılma direnci verileri ortalama, minimum ve maksimum değerler olarak sunuldu. İstatistiksel karşılaştırmalar IBM SPSS v23 (ABD) ile yapıldı. Kolmogorow-Smirnov testi sonucuna göre verilerin normal dağılım göstermesi ile ANOVA ve post hoc Tukey testleri uygulandı. İstatistiksel anlamlıık düzeyi 0,05 olarak alındı.

\section{BULGULAR}

Her bir grup için ortalama, minimum ve maksimum kırılma dayanımı değerleri Tablo 1'de gösterilmiştir.

Tablo 1. Gruplardan elde edilen ortalama (Standart Sapma) ile istatistiksel karşılaştırmalar, minimum ve maksimum değerler (Newton).

\begin{tabular}{|c|c|c|c|}
\hline Gruplar & Ortalama (SD) & Minimum & Maksimum \\
\hline OSNG & $674,2(7,91) a$ & 644,4 & 705,9 \\
\hline K3XF & $597,6(6,08) a$ & 570,3 & 627,7 \\
\hline PTG & $658,9(15,28) a$ & 631,3 & 682,6 \\
\hline
\end{tabular}

Aynı harf (a) ile gösterilen gruplar arasında fark vardır. $P<0,05$, Tukey's Test

OSNG grubu diğer gruplara göre anlamlı derecede daha yüksek kırılma dayanım değeri gösterirken $(P<0,05)$, K3XF grubu diğer çalışma gruplarına kıyasla daha düşük kırılma dayanım değerine neden olmuştur $(\mathrm{P}<0,05)$. PTG grubunun ise, OSNG grubundan istatistiksel olarak daha düşük, K3XF grubundan ise daha yüksek kırılma dayanım değeri gösterdiği tespit edilmiştir $(P<0,05)$. Tüm örneklerin kırıma dayanım değer dağılımları grafiği Resim 1'de gösterilmiştir.

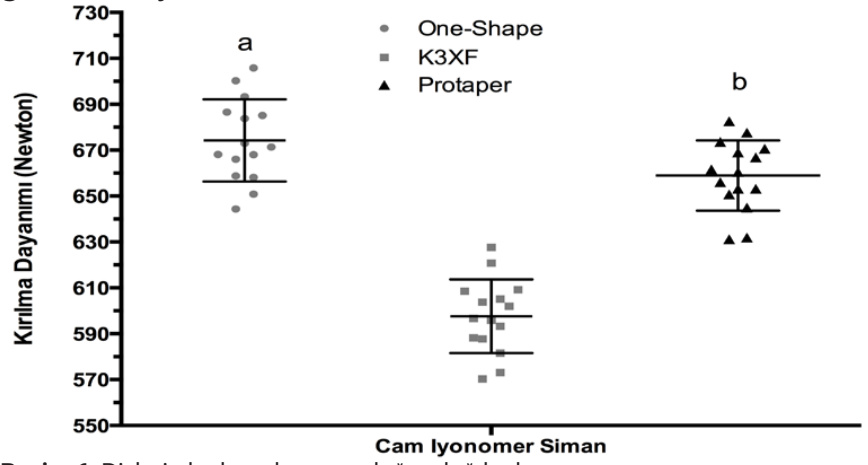

Resim 1: Dişlerin kırılma dayanım değer dağııımları

OSNG, K3XF ve PTG rotary sistemleri ile yapılan preparasyonun post-core restorasyonu sonrası, kök dentin kırılma dayanımı üzerindeki etkisinin incelendiği bu in vitro çalışmada, tüm gruplar arasında kırılma direnci değerleri açısından istatistiksel olarak anlamlı fark görülmüştür $(\mathrm{P}<0,05)$ 


\section{TARTIŞMA}

Endodontide kök kanal tedavisinin başarısında, kök kanallarından bakteri, smear tabakası, enfekte pulpa ve debrislerin uzaklaştırılmasında en önemli aşama biomekanik preparasyondur. ${ }^{26}$ Endodontik tedavilerde kök kanallarının preparasyonunda basamak oluşumu, kanal transportasyonu ve perforasyonlar gibi istenmeyen komplikasyonlar meydana gelebilir. ${ }^{2-4}$ Aynı zamanda biyomekanik preparasyon sırasında kök kırıkları ve dentinde derin çatlaklar gibi istenmeyen sonuçlar dişin çekilmesiyle sonuçlanabilen komplikasyonlardır. 5,27

Literatürde, endodontik tedavilerde kullanılan materyallerin mekanik özelliklerinin araştıııldığı çalışmalarda, kullanılacak dişlerin çekim sonrasından laboratuvar işlemlerine kadar geçen sürede bekletilme şartları çalışma sonuçlarını etkileyebilir. Bu nedenle, dişin dentini üzerine minimum derecede etkisi olan distile suyun, kök dentini üzerinde yapılan araştırmalarda tercih edilmesi tavsiye edilmektedir. ${ }^{28} \mathrm{Bu}$ bağlamda, araştırmamızda diğer çalışmalarda olduğu gibi dişler uygulama süreci başlayıncaya kadar distile su içerisinde muhafaza edildi. ${ }^{8}$

In vitro araştırmalarda, çalışma sonucunu etkileyebilecek ve dişe gelen kuvvetin dağılımında pay sahibi olan periodontal ligamentin taklit edilmesi gerekir. Bunun başlıca nedeni, ligamentin sahip olduğu viskoelastik özellikleri ile dişlere gelen çiğneme kuvvetlerinin yarattığı gerilimi dağıtmada önemli rol oynamasıdır. ${ }^{29}$ Bu nedenle, çalışmamızda diğer araştırmalarda olduğu gibi periodontal ligamenti taklit etmek amacıyla polieter ölçü maddesi tercih edildi. ${ }^{30,31}$ Bu elastomerik ölçü materyallerinin lineer olmayan viskoelastik özellikleri ile periodontal ligamente benzer olmaları çalışmamızda in vivo koşulları daha iyi yansıtmamızı sağlamıştır. ${ }^{32,33}$

Kök kanal tedavisi esnasında kullanılan sodyum hipokloritin, irigasyon sırasında kök dentini üzerinde mekanik anlamda değişikliğe neden olabileceği ortaya konmuştur. ${ }^{34}$ Özellikle yüksek konsantrasyonda kullanılan NaO$\mathrm{Cl}^{\prime}$ nin diğer bir irrigasyon solüsyonu olan serum fizyolojiğe kıyasla kök dentininde daha fazla esneklik dayanımı ve elastik modülü düşüşüne neden olduğu belirtilmiştir. ${ }^{35}$ $\mathrm{NaOCl}$ ve EDTA irigasyon solüsyonları üzerine yapılan bir çalışmada, dentin mikro sertliğinin her iki solüsyonun kullanımında da düştüğü ancak diğer bir çalışma grubu olan distile suyun dentinin mikrosertliğini üzerine etkisinin olmadığını vurgulamışlardır. ${ }^{36}$ Yapılan başka bir araştırmada da farklı konsantrasyonlarda kullanılan NaOCl'nin kök dentini üzerindeki yapısal ve mekanik etkileri incelenmiş, çalışma sonucunda distile su ve \%1 konsantrasyonundaki NaOCl'nin kök dentininin esneklik dayanımı ve elastik modülünde kayda değer bir değişikliğe neden olmadığını belirtmişlerdir. ${ }^{37}$ Çalışmamızda da, in vivo koşulları elde edebilmek ve daha sağlıklı sonuçlar ortaya koymak amacıyla tüm gruplarda eşit miktarda \%1 kon- santrasyonunda $\mathrm{NaOCl}$ solüsyonu ile irrigasyon yapıldı. Endodontik tedavi esnasında uygulanan işlemlerin kök dentininde oluşturabileceği etkileri araştırmak için, dişlerin kırılma dirençlerinin ölçülmesi ve stres dağılımı gibi çeşitli yöntemler tanımlanmıştır. ${ }^{38-41}$ Çalışmamızın metoduna benzer yapılan çalışmalarda da dışardan kuvvet verilerek, bu yük kök kırılana kadar devam edecek şekilde uygulanır. ${ }^{42}$ Çalışmamızda da dişlerin kırılma direnç değerleri kökler kırılana kadar vertikal kuvvet uygulanarak ölçüldü.

Çalışma sırasında tüm örneklerde postun yapıştırılmasında endodontik işlem ile yapılan restorasyon uygulamalarında yaygın kullanım alanına sahip bir materyal olması nedeni cam iyonomer siman kullanıldı. ${ }^{23}$

Çalışmamızda kullanılan sistemler OSNG, PTG ve K3XF sistemleridir. Literatürde, K3XF ve PTG rotary sistemlerinin post uygulanmasını takiben kök dentininde meydana gelebilen dentin çatlağı ve kırılmalar üzerine etkilerini inceleyen bir araştırma bulunmamaktadır. Ayrıca, K3XF'in kök kırıkları üzerine etkisi ile ilgili literatürde herhangi bir çalışma bulunmaması nedeniyle K3XF ile ilgili bulgular tartışılamamıştır. Kullanılan aletlerin kök dentin üzerinde farklı derecelerde hasara yol açmalarının nedenlerinden biri aletlerin farklı enine kesit tasarımları olduğu ortaya konmuştur. ${ }^{43}$ Farklı döner sistemlerin vertikal kök kırıkları üzerine etkilerinin incelendiği bir çalışmada, ProTaper eğelerinin kök dentin yüzeyinde daha fazla strese yol açtığı ve daha yüksek derecede gerilimlere neden olduğu ortaya konmuştur. ${ }^{44}$ Kök kanal preparasyon sistemlerinin mikro çatlak oluşturma üzerine etkisinin incelendiği bir başka çalışmada, ProTaper sisteminin daha yüksek oranda dentin çatlağına neden olduğu belirtilmiştir. ${ }^{45}$ Çalışmamızda elde ettiğimiz sonuç bahsedilen çalışma sonuçları ile uyumludur. Bu tip sistemlerde ortaya çıkan bu sonucun, şekillendirme esnasında aletlerin kök kanallarında oluşturdukları döngüsel kuvvetlerin etkisi ile ortaya çıktığı düşünülebilir. ${ }^{46}$ Kök dentininde bu şekilde oluşan hasarların dereceleri, kullanılan aletlerin sabit veya artan açılanmasına, çapraz kesit geometrisine, yiv formuna ve uç tasarımına göre değişiklik gösterebilir. ${ }^{46}$ PTG grubu, OSNG grubuna göre daha düşük kök dentin dayanım değerlerinin oluşmasına neden olmuştur. Bu, döner aletlerin kök dentininde daha az mikro çatlak oluşmasını sağlayan, kullanılan aletlerle kök dentini arasındaki temas alanı olarak tanımlanan radyal alandan kaynaklabilir. Ancak ProTaper NiTi sistemlerde radyal sahanın yer almaması, çalışmamızda şekillendirme esnasında kanal duvarlarına daha fazla kuvvetin yansımasına neden olmuş olabilir. Bu durumun örneklerimizde kök dentininde mikro çatlak oluşum riskini arttırmış olabileceğini düşünmekteyiz. Mikro çatlak oluşmasında diğer bir etki mekanizmasının kullanılan eğelerin taper açıları olduğu belirtilmiştir. ${ }^{47}$ Yapılan bir in vitro araştırma açısız 
olan kanal eğelerinin preparasyon sırasında kök kanal duvarlarına bir zarar vermediği ortaya konmuştur. ${ }^{47} \mathrm{Bi}-$ zim çalışmamızda kullanılan eğe sistemleri arasında PTG sistemi, kök kanalının apikal kısmının preparasyonu için kullanılan aletler açısından en yüksek açıya sahip olan NiTi sistemdir. Kanalların preparasyonunda PTG sisteminin kullanıldığı örneklerde OSNG sisteminin kullanıldığı örneklere kıyasla daha düşük dentin kırığı dayanımı değerleri çıkmasının eğelerin farklı açı değerlerinden kaynaklandığını düşünmekteyiz.

OSNG grubu diğer sistemlerden daha yüksek kırılma dayanımı değerleri ortaya koymuştur. Bunu eğe sisteminin tek kullanımlık ve tek eğe sistemi olmasına aynı zamanda kesitsel tasarımı ile ilgili sürekli rotasyonda daha iyi kesme verimliliğine sahip olmasına bağlayabiliriz. One Shape (OS, MicroMega, Besancon, Fransa), tek bir eğe ile kök kanalı şekillendirme yapmayı mümkün kılan döner enstrüman sistemidir. Eğe şaftı boyunca değişen 3 farklı yatay kesitten oluşur. Bu alanlardan birincisi, eğenin apikal üçte birinde olan ve 3 kesici kenardan oluşan alandır. Eğenin orta üçte birlik kısmında yatay enine kesitte kesici kenarların sayısı 3 ile 2 arasında değişir. Son olarak, koronal üçüncü kısımdaki yatay kesitte 2 şekilli kesici kenar bulunur. ${ }^{48-50}$ Üretici firmaya göre, eğenin değişken yatay kesitli tasarımı, vidalanan eğenin kanal duvarlarına etkisini azaltır. Bu bağlamda, OSNG'nin 3 ile 2 kesici kenar arasında giderek değişen üç farklı seviyede değişken kesitlere sahip olması kök kanallarındaki stresin azalmasını ve böylece kırılma dayanımının artmasını sağladığını düşünmekteyiz.

\section{SONUÇ}

Son zamanlarda üstün özellikleri öne sürülen farklı preparasyon sistemleri ile kök kanal preparasyonunun yapılan protetik tedavi sonrası dişlerin dayanıkııı̆ına etkisi dişin ağızda daha uzun süre fonksiyon görmesi açısından önem taşımaktadır. Çalışmamızda her üç preparasyon sisteminde de farklı değerlerdeki kuvvetler altında kök kırıkları meydana gelmiştir. Fakat en yüksek kırılma dayanım değeri OSNG sağlamıştır.

Bu bilgiler ışığında, çalışmamızdan elde edilen verilere göre farklı rotary sistemleri ile kök kanal preparasyonunun protezlerin uzun süreli kullanımında daha dayanıklı bir altyapı elde etme noktasında kök dentin kırılma dayanımı üzerine etkisi olduğunu ve OSNG sisteminin uzun süreli tedavi başarısı göz önüne alındığında kök kanal preparasyonunda öncelikli olarak tercih edilebileceğini düşünmekteyiz.

Çalışmamızda kullanılan tüm sistemler dentin çatlağına sebep olmuştur. Dentin çatlağı oluşumuna sebep olmayan sistemler ile daha başarılı ve uzun ömürlü tedaviler gerçekleştirilebileceği için, dentinde minimum hasara neden olan kök kanal şekillendirme sistemlerine ihtiyaç vardır. Ayrıca, kök kanal şekillendirme sistemlerinin neden olduğu dentin çatlaklarını inceleyen daha fazla in-vitro, ex-vivo ve in-vivo çalışmaya intiyaç vardır.

\section{KAYNAKLAR}

1.Peters OA. Current challenges and concepts in the preparation of root canal systems: a review. J Endod 2004; 30: 559-567.

2.Tsesis I, Rosenberg E, Faivishevsky V, Kfir A, Katz M, Rosen E. Prevalence and associated periodontal status of teeth with root perforation: a retrospective study of 2,002 patients' medical records. J Endod 2010; 36: 797-800.

3.Aydin B, Kose T, Caliskan MK. Effectiveness of HERO 642 versus Hedstrom files for removing gutta-percha fillings in curved root canals: an ex vivo study. Int Endod $J$ 2009; 42: 1050-1056.

4.Cuje J, Bargholz C, Hulsmann M. The outcome of retained instrument removal in a specialist practice. Int Endod J 2010; 43: 545-554.

5.Wilcox LR, Roskelley C, Sutton T. The relationship of root canal enlargement to finger-spreader induced vertical root fracture. J Endod 1997; 23: 533-534.

6.Shemesh H, Roeleveld AC, Wesselink PR, Wu MK. Damage to root dentin during retreatment procedures. J Endod 2011; 37: 63-66.

7.Kim HC, Lee MH, Yum J, Versluis A, Lee CJ, Kim BM. Potential relationship between design of nickel-titanium rotary instruments and vertical root fracture. J Endod 2010; 36: 1195-1199.

8. Shemesh $\mathrm{H}$, Bier CA, Wu MK, Tanomaru-Filho M, Wesselink PR. The effects of canal preparation and filling on the incidence of dentinal defects. Int Endod J 2009; 42: 208-213.

9.Fonzar F, Mollo A, Venturi M, Pini P, Fabian Fonzar R, Trullenque-Eriksson A, Esposito M. Single versus two visits with 1-week intracanal calcium hydroxide medication for endodontic treatment: One-year post-treatment results from a multicentre randomised controlled trial. Eur J Oral Implantol 2017; 10: 29-41.

10.Garlapati TG, Krithikadatta J, Natanasabapathy V. Fracture resistance of endodontically treated teeth restored with short fiber composite used as a core material-An in vitro study. J Prosthodont Res 2017; Mar 6. doi: 10.1016/j.jpor.2017.02.001.

11.Pedullà E, Plotino G, Scibilia M, Grande NM, DE Santis D, Pardo A, Testarelli L, Gambarini G. Cyclic fatigue comparison among endodontic instruments with similar cross section and different surface coating. Minerva Stomatol 2016; Nov 9.

12.Chieruzzi M, Pagano S, Cianetti $S$, Lombardo G, Kenny JM, Torre L. Effect of fibre posts, bone losses and fibre content on the biomechanical behaviour of endodontically treated teeth: 3D-finite element analysis. Mater Sci 
Eng C Mater Biol Appl 2017; 74: 334-346.

13.Vadavadagi SV, Dhananjaya KM, Yadahalli RP, Lahari M, Shetty SR, Bhavana BL. Comparison of Different Post Systems for Fracture Resistance: An in vitro Study. J Contemp Dent Pract 2017; 18: 205-208.

14. Mizuno Y, Gonda T, Takahashi T, Tomita A, Maeda Y. Root Fracture of Abutment Teeth for Partial Removable Dental Prostheses. Int J Prosthodont 2016; 29: 461-466. 15.Endodontically treated teeth: Characteristics and considerations to restore them. http://dx.doi.org/10.1016/j. jpor.2010.07.003.

16.Gambarini G, Di Nardo D, Miccoli G, Guerra F, Di Giorgio R, Di Giorgio G, Glassman G, Piasecki L, Testarelli $L$. The Influence of a New Clinical Motion for Endodontic Instruments on the Incidence of Postoperative Pain. Clin Ter 2017; doi: 10.7417/CT.2017.1977.

17.Khaledi AA, Sheykhian S, Khodaei A. Evaluation of Retention of two Different Cast Post-Core Systems and Fracture Resistance of the Restored Teeth. J Dent (Shiraz) 2015; 16: 121-128.

18.Pereira JR, do Valle AL, Shiratori FK, Ghizoni JS, Bonfante EA. The effect of post material on the characteristic strength of fatigued endodontically treated teeth. J Prosthet Dent 2014; 112: 1225-1230.

19.Jindal S, Jindal R, Gupta K, Mahajan S, Garg S. Comparative evaluation of the reinforcing effect of different post systems in the restoration of endodontically treated human anterior teeth at two different lengths of post space preparation- an in vitro study. J Dent (Tehran) 2013; 10: 124-133.

20.Sangwan B, Rishi R, Seal M, Jain K, Dutt P, Talukdar P. An in vitro Evaluation of Fracture Resistance of endodontically treated Teeth with Different Restorative Materials. J Contemp Dent Pract 2016; 17: 549-552.

21.Tavanafar $S$, Karimpour $A$, Karimpour $H$, Mohammed Saleh A, Hamed Saeed M. Effect of Different Instrumentation Techniques on Vertical Root Fracture Resistance of Endodontically Treated Teeth. J Dent (Shiraz) 2015; 16: 50-55.

22.Koch AT, Binus SM, Holzschuh B, Petschelt A, Powers JM, Berthold C. Restoration of endodontically treated teeth with major hard tissue loss-influence of post surface design on pull-out bond strength of fiber-reinforced composite posts. Dent Traumatol 2014; 30: 270-279.

23.Pereira JR, da Rosa RA, do Valle AL, Ghizoni JS, Só MV, Shiratori FK. The influence of different cements on the pull-out bond strength of fiber posts. J Prosthet Dent 2014; 112: 59-63.

24.Bitter K, Aschendorff L, Neumann K, Blunck U, Sterzenbach $\mathrm{G}$. Do chlorhexidine and ethanol improve bond strength and durability of adhesion of fiber posts inside the root canal? Clin Oral Investig 2014; 18: 927-934.

25.Rocca GT, Rizcalla N, Krejci I. Fiber-reinforced resin coating for endocrown preparations: a technical report. Oper Dent 2013; 38: 242-248.

26. Yoldas O, Yilmaz S, Atakan G, Kuden C, Kasan Z. Dentinal microcrack formation during root canal preparations by different $\mathrm{NiTi}$ rotary instruments and the self-adjusting file. J Endod 2012; 38: 232-235.

27. Tamse A, Fuss Z, Lustig J, Kaplavi J. An evaluation of endodontically treated vertically fractured teeth. J Endod 1999; 25: 506-508.

28.Strawn SE, White JM, Marshall GW, Gee L, Goodis HE, Marshall SJ. Spectroscopic changes in human dentine exposed to various storage solutions--short term. J Dent 1996; 24: 417-423.

29.Milani AS, Froughreyhani M, Rahimi S, Jafarabadi MA, Paksefat S. The effect of root canal preparation on the development of dentin cracks. Iran Endod J 2012; 7: 177182.

30.Soares CJ, Martins LR, Pfeifer JM, Giannini M. Fracture resistance of teeth restored with indirect-composite and ceramic inlay systems. Quintessence Int 2004; 35: 281286.

31.Rosentritt M, Furer C, Behr M, Lang R, Handel G. Comparison of in vitro fracture strength of metallic and tooth-coloured posts and cores. J Oral Rehabil 2000; 27: 595-601.

32.Jamani KD, Harrington E, Wilson HJ. Rigidity of elastomeric impression materials. J Oral Rehabil 1989; 16 : 241-248.

33. Yoshida N, Koga Y, Peng CL, Tanaka E, Kobayashi K. In vivo measurement of the elastic modulus of the human periodontal ligament. Med Eng Phys 2001; 23: 567-572. 34.Pascon FM, Kantovitz KR, Sacramento PA, Nobre-dos-Santos M, Puppin-Rontani RM. Effect of sodium hypochlorite on dentine mechanical properties. A review. J Dent 2009; 37: 903-908.

35.Sim TP, Knowles JC, Ng YL, Shelton J, Gulabivala K. Effect of sodium hypochlorite on mechanical properties of dentine and tooth surface strain. Int Endod J 2001; 34: 120-132.

36.Zaparolli D, Saquy PC, Cruz-Filho AM. Effect of sodium hypochlorite and EDTA irrigation, individually and in alternation, on dentin microhardness at the furcation area of mandibular molars. Braz Dent J 2012; 23: 654-658.

37. Marending M, Luder HU, Brunner TJ, Knecht S, Stark WJ, Zehnder M. Effect of sodium hypochlorite on human root dentine--mechanical, chemical and structural evaluation. Int Endod J 2007; 40: 786-793

38. Lertchirakarn V, Palamara JE, Messer HH. Load and strain during lateral condensation and vertical root fracture. J Endod 1999; 25: 99-104.

39.Saw LH, Messer HH. Root strains associated with different obturation techniques. J Endod 1995; 21:314-320. 40.Obermayr G, Walton RE, Leary JM, Krell KV. Vertical 
root fracture and relative deformation during obturation and post cementation. J Prosthet Dent 1991; 66: 181-187. 41. Mayhew JT, Eleazer PD, Hnat WP. Stress analysis of human tooth root using various root canal instruments. $J$ Endod 2000; 26: 523-524.

42.Ribeiro FC, Souza-Gabriel AE, Marchesan MA, Alfredo E, Silva-Sousa YT, Sousa-Neto MD. Influence of different endodontic filling materials on root fracture susceptibility. J Dent 2008; 36: 69-73.

43.Burklein $S$, Tsotsis $P$, Schafer E. Incidence of dentinal defects after root canal preparation: reciprocating versus rotary instrumentation. J Endod 2013; 39: 501-504.

44.Kim HC, Lee MH, Yum J, Versluis A, Lee CJ, Kim BM. Potential relationship between design of nickel-titanium rotary instruments and vertical root fracture. $\mathrm{J}$ Endod 2010; 36: 1195-1199.

45.Liu R, Hou BX, Wesselink PR, Wu MK, Shemesh $H$. The incidence of root microcracks caused by 3 different single-file systems versus the ProTaper system. J Endod 2013; 39: 1054-1056.

46. Liu R, Kaiwar A, Shemesh H, Wesselink PR, Hou B, Wu MK. Incidence of apical root cracks and apical dentinal detachments after canal preparation with hand and rotary files at different instrumentation lengths. $\mathrm{J}$ Endod 2013; 39: 129-132.

47.Bier CA, Shemesh $H$, Tanomaru-Filho $M$, Wesselink $\mathrm{PR}, \mathrm{Wu}$ MK. The ability of different nickel-titanium rotary instruments to induce dentinal damage during canal preparation. J Endod 2009; 35: 236-238.

48.Çapar ID, Ertaş $H$, Arslan H. Comparison of cyclic fatigue resistance of novel nickel-titanium rotary instruments. Aust Endod J 2015; 41: 24-28.

49.Bürklein S, Benten S, Schäfer E. Shaping ability of different single-file systems in severely curved root canals of extracted teeth. Int Endod J 2013; 46:590-597.

50.Micro Mega. The One Shape Brochure. Available at: http://micro-mega.com/en/one- shape-newgeneration/ documentations/. Accessed March 15, 2016. 
